\title{
ASPECTOS EPISTEMOLÓGICOS DA CIÊNCIA DA INFORMAÇÃO E O COMPORTAMENTO INFORMACIONAL: DIÁlOGOS COM BORKO, LE COADIC E SARACEVIC
}

EPISTEMOLOGICAL ASPECTS OF INFORMATION SCIENCE AND INFORMAL BEHAVIOR: DIALOGUES WITH BORKO, LE COADIC AND SARACEVIC

ASPECTOS EPISTEMOLÓGICOS DE LA CIENCIA DE LA INFORMACIÓN

Y EL COMPORTAMIENTO INFORMACIONAL:

DIÁLOGOS CON BORKO, LE COADIC Y SARACEVIC

1Jorge Santa Anna

Universidade Federal de Minas Gerais ${ }^{1}$

Correspondência

1Jorge Santa Anna

Universidade Federal de Minas Gerais,

Belo Horizonte, MG - Brasil.

Email: professorjorgeufes@gmail.com

ORCID: http://orcid.org/0000-0002-0709-3639

Submetido em: 10/10/2017

Aceito em: 19/12/2017

Publicado em: 18/01/2018

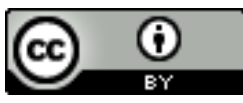

JITA: CE. Literacy 
RESUMO: Os estudos sobre usuários e seus comportamentos no que tange à busca por informação têm demonstrado o quanto o aspecto humano-social tem sido valorizado pelas ciências, sobretudo na Ciência da Informação. Portanto, apresenta-se pesquisa preliminar, cujo objetivo é discorrer alguns aspectos epistemológicos da Ciência da Informação, bem como os estudos do comportamento informacional, tendo como base teórica as reflexões apresentadas por Borko, Le Coadic e Saracevic. Por meio de pesquisa descritiva e bibliográfica de abordagem dedutiva, confirmou-se que a Ciência da Informação estuda o objeto informação e os procedimentos para coleta, armazenagem e uso desse recurso, caracterizando-se como uma ciência interdisciplinar, influenciada pelas tecnologias da informação e comunicação, cuja origem desse campo científico remete aos reflexos do desenvolvimento científico e tecnológico do século XX. Além disso, concluiuse que os estudos das necessidades e do uso da informação, com foco no usuário, viabiliza a importância do ser humano, como principal elemento do processo informacional, sendo que os estudos vêm se aperfeiçoando, em que são investigadas questões comportamentais quanto ao uso dos recursos, produtos, serviços e sistemas de informação.

PAlavraS-Chave: Ciência da Informação. Estudo de uso. Estudo de usuários. Comportamento informacional.

ABSTRACT: The studies on users and their behaviors regarding the search for information have demonstrated how much the human-social aspect has been valued by the sciences, especially in Information Science. Therefore, preliminary research is presented, whose objective is to discuss some epistemological aspects of Information Science, as well as the studies of informational behavior, based on the theoretical considerations presented by Borko, Le Coadic and Saracevic. Through a descriptive and bibliographical research of deductive approach, it was confirmed that Information Science studies the information object and the procedures for collection, storage and use of this resource, characterizing itself as an interdisciplinary science, influenced by information and communication technologies, whose origins of this scientific field refer to the reflections of the scientific and technological development of the twentieth century. In addition, it was concluded that the studies of the needs and the use of information, with a focus on the user, enables the importance of the human being, as the main element of the informational process, and studies are being improved, in which behavioral issues are investigated Use of resources, products, services and information systems.

KEYWORDS: Information Science. Use study. Study of users. Informational behavior.

RESUMEN: Los estudios sobre usuarios y sus comportamientos en lo que se refiere a la búsqueda de información han demostrado cuánto el aspecto humano-social ha sido valorado por las ciencias, sobre todo en la Ciencia de la Información. Por lo tanto, se presenta una investigación preliminar, cuyo objetivo es discurrir algunos aspectos epistemológicos de la Ciencia de la Información, así como los estudios del comportamiento informacional, teniendo como base teórica las reflexiones presentadas por Borko, Le Coadic y Saracevic. A través de una investigación descriptiva y bibliográfica de enfoque deductivo, se confirmó que la Ciencia de la Información estudia el objeto de información y los procedimientos para la recolección, almacenamiento y uso de ese recurso, caracterizándose como una ciencia interdisciplinaria, influenciada por las tecnologías de la información y comunicación, cuyos orígenes de ese campo científico remiten a los reflejos del desarrollo científico y tecnológico del siglo XX. Además, se concluyó que los estudios de las necesidades y del uso de la información, con foco en el usuario, viabiliza la importancia del ser humano, como principal elemento del proceso informacional, siendo que los estudios vienen perfeccionándose, en que se investigan cuestiones comportamentales En cuanto al uso de los recursos, productos, servicios y sistemas de información.

Palabras Clave: Ciencia de la Información. Estudio de uso. Estudio de usuarios. Comportamiento informativo. 


\section{INTRODUÇÃ̃o}

A Ciência da Informação vem se constituindo como um campo de conhecimento de grande contribuição para o desenvolvimento da sociedade contemporânea, sobretudo por propor métodos, teorias e técnicas direcionadas ao gerenciamento da informação e do conhecimento, considerados, nos dias de hoje, a base para o desenvolvimento social e econômico.

A variedade de estudos ofertados por essa ciência tem proporcionado seu reconhecimento e valorização, sobretudo por viabilizar estratégias para resolução do problema informacional, principalmente no que se refere ao tratamento, gestão e uso da informação nos mais diferentes segmentos sociais.

Esse fato demonstra as potencialidades inerentes à Ciência da Informação que, mesmo sendo considerada como uma ciência relativamente jovem, seu aspecto interdisciplinar, tecnológico e humano-social tem vislumbrado um futuro promissor no que se refere às contribuições dessa área para a ciência e sociedade.

No decurso de aproximadamente quatro décadas de existência, a Ciência da Informação tem ampliado seu escopo de atuação, desenvolvendo pesquisas dos mais variados assuntos e enriquecendo sua base teórico-metodológica, por conseguinte rompendo fronteiras e paradigmas tradicionais, considerados, no atual momento, como incapazes de atender as necessidades específicas e a constante instabilidade e competitividade de um mercado cada dia mais globalizado.

As demandas sociais empíricas requeridas à Ciência da Informação tornam esse campo do saber como uma ciência social, como nos ensinam Shera (1971), Saracevic (1996, 1999), Capurro (2000), Le Coadic (2004a), dentre outros. A princípio, essa ciência tem se dedicado, sobremaneira, aos estudos sobre as tecnologias e a capacidade em se armazenar/disseminar o conhecimento registrado. Todavia, as diversas manifestações da informação na sociedade têm viabilizado novas possibilidades para a Ciência da Informação, como relatado por Saracevic (1999), Buckland (1991), dentre outros.

Além de se apresentar como uma ciência voltada ao gerenciamento da informação registrada, tendo maior preocupação com os registros gráficos do conhecimento e os processos comunicacionais (LE COADIC, 2004a), não há como negar que essa ciência tem adquirido, nos últimos anos, uma característica eminentemente humana, sobretudo por abordar questões relativas à recuperação da informação, por conseguinte, faz-se necessário, primariamente, identificar as necessidades informacionais dos usuários, bem como entender o comportamento humano em face do uso dos sistemas de informação, sobretudo os informatizados.

Assim, em virtude das múltiplas necessidades e exigências sociais, os estudos 
contemplados pela Ciência da Informação manifestam-se sobre variadas vertentes de pesquisa, tanto sob um viés epistemológico quanto pragmático. As escolas de formação e aperfeiçoamento, principalmente no Brasil, têm ampliado suas linhas de investigação, o que desencadeou a formação de diferentes subcampos contemplados por essa ciência.

Portanto, é comum encontrar estudos tanto amplos quanto específicos, contemplando desde questões técnicas quanto humanistas. Essas diversas questões investigadas abarcam problemas relativos à organização e gestão do conhecimento, à elaboração, aplicação e uso de tecnologias, às técnicas e metodologias para tratamento da informação registrada, dentre outras linhas de investigação, como também há um enfoque direcionado ao fator humano, tendo em vista estudos sobre uso da informação, comportamento informacional, questões culturais, memória histórica e social, dentre outros aspectos analisados por pesquisadores.

Em linhas gerais, a dimensão técnico-social é bem-vinda por evidenciar a amplitude de atuação da Ciência da Informação, tal como refletido no estudo de Radamés Linares (2005). Essa ciência se consolida a partir da conjunção de diferentes ramos de investigação, caracterizada como campo da prática profissional e investigação científica, mas, abordando, especificamente, “[...] a comunicação efetiva da informação e objeto da informação, particularmente conhecimento registrado entre o contexto social, organizacional e necessidade individual para o uso da informação [...]" (SARACEVIC, 2009, p. 1, tradução nossa, grifo nosso).

Certamente, a diversidade dos estudos realizados por essa área é justificada, primeiramente, por sua natureza interdisciplinar, sustentada em um arcabouço multiprofissional. Contudo, nas últimas décadas, o interesse de pesquisa quanto ao aspecto humano-social tem se intensificado. Desse modo, a estrutura intelectual da Ciência da Informação, segundo o autor supracitado, tem se destacado, sobremaneira, na área de recuperação de informação, como também, na área do comportamento informacional humano e estudos de métricas.

A literatura é abrangente no que se refere ao desenvolvimento de estudos sobre uso e usuários da informação. Trata-se de uma tendência que abrange diversas áreas do conhecimento, em que o usuário tornou-se o paradigma principal nos dias atuais. A preocupação com o usuário vem sendo notada desde as últimas décadas do século $\mathrm{XX}$, sobretudo com o desenvolvimento de sistemas de recuperação da informação automatizados, em que esses sistemas têm sido desenvolvidos com base no comportamento do usuário, tendo em vista adequar-se às necessidades específicas desses indivíduos, em face do processo de busca e recuperação da informação, como relatado nos estudos de Lancaster (2004).

Nesse contexto, embora a Ciência da Informação vem se consolidando na sociedade atual, como também o aspecto humano-social dessa ciência vem sendo desprendido por meio dos estudos de uso e usuários da informação, por conseguinte, manifestam-se linhas de 
pesquisa direcionadas ao comportamento informacional, o qual se configura como um subcampo da Ciência da Informação - tal como descrito por Rolim e Cendón (2013) - muitas questões ainda carecem de melhor esclarecimentos, seja quanto aos aspectos epistemológicos, como conceitos, características e historicidade, como também, questões relacionadas ao comportamento do usuário quando da busca da informação.

No que se refere ao comportamento informacional, Rolim e Cendón (2013) demonstraram o crescimento dessa temática de pesquisa, nos últimos anos, no entanto, evidenciaram carência de bases teóricas desses estudos, sendo necessário aprofundar essas bases, uma vez que elas servem como ponto de orientação para a coleta e análise de dados nos estudos de usuários.

Sendo assim, este artigo constitui uma pesquisa preliminar $^{1}$, cujo objetivo é discorrer alguns aspectos epistemológicos da Ciência da Informação à luz da literatura especializada, bem como os estudos do comportamento informacional, tendo como base teórica as reflexões apresentadas por Borko, Le Coadic e Saracevic. Para tanto, delinearam-se os seguintes objetivos de natureza específica: apresentar conceitos e características inerentes ao campo da Ciência da Informação; contextualizar a gênese e desenvolvimento da Ciência da Informação; dissertar sobre o aspecto humano e social relativo a essa ciência; e demonstrar como tem sido tratado a questão do comportamento informacional no âmbito da Ciência da Informação.

Como metodologia, considerando a abordagem de pesquisa, recorreu-se ao método dedutivo, criado por René Descartes, no século XVII. Por meio do método dedutivo, é possível chegar a resultados e conclusões mediante a razão. Parte-se das teorias e leis gerais para se chegar a determinação ou inferência de fenômenos. Inicia a investigação por meio de uma análise geral, especificando-se os assuntos, a fim de se delimitar o objeto de investigação. Dessa forma, no âmbito deste artigo, inicia-se a reflexão sobre questões epistemológicas da Ciência da Informação, tais como conceitos, características e historicidade, delimitando-se ao tema sobre uso e comportamento informacional.

No que se refere aos procedimentos técnicos utilizados, considerou-se a classificação proposta por Vergara (2007), ou seja, os procedimentos classificam-se quanto aos meios e quanto aos fins. Desse modo, quanto aos fins, a pesquisa caracteriza-se como descritiva, pois são discorridos aspectos relativos a um campo de conhecimento, a Ciência da Informação. Quanto aos meios, a pesquisa é bibliográfica, uma vez que se recorre a estudos desenvolvidos por autores consagrados na área, tendo como referencial as reflexões de Borko, Le Coadic e Saracevic.

\footnotetext{
${ }^{1} \mathrm{O}$ estudo ora apresentado teve sua gênese a partir das reflexões propostas na disciplina "Estudos avançados em Informação", do Programa de Pós-Graduação em Gestão e Organização do Conhecimento (ECI/UFMG), cuja proposta preliminar aqui apresentada representa a base de fomento para a elaboração de uma pesquisa mais aprofundada (dissertação), acerca do uso da informação e do comportamento do usuário em face da gestão de um portal de periódico.
}

\begin{tabular}{l|l|l|l|l|l}
\hline (C) RDBCI: Rev. Digit. Bibliotecon. Cienc. Inf. & Campinas, SP & v.16 & n.2 & p. 344-364 & maio/ago. 2018 \\
\hline
\end{tabular} 
Importante mencionar que alguns argumentos apresentados também foram retirados de obras de outros autores, de modo a enriquecer as discussões. No entanto, a base de investigação está nesses três clássicos, porque: Borko foi quem apresentou o primeiro conceito científico para Ciência da Informação, na década de 1960, sendo utilizado para análise o artigo publicado em 1968, por esse ter sido uma das publicações precursoras da área da Ciência da Informação, como também um dos mais citados ao longo dos anos; em Le Coadic, recorreu-se ao livro de 2004, por essa obra discorrer sobre o fator humano e social da Ciência da Informação e as possíveis relações desse campo de conhecimento com as práticas infocomunicativas, e a um artigo, também publicado em 2004, cuja temática abordou os paradigmas no âmbito do uso dos sistemas de informação; e, por sua vez, Saracevic, porque tem sido um dos autores mais citados no Brasil, enfatizando uma abordagem técnico-humana sobre a Ciência da Informação, tendo como publicações mas citadas em todo o mundo os artigos publicados em 1996, 1999 e 2009.

Quanto aos dados biográficos desses teóricos, ressalta-se que Borko nasceu na cidade de Nova Iorque (EUA) e estudou Psicologia na Universidade de Califórnia em Los Ángeles, no ano de 1948, ampliando seus estudos em Psicologia por meio do Mestrado e Doutorado. Além de atuar no campo da pesquisa e docência, esse pesquisador foi presidente da Sociedade Americana de Ciência da Informação, em 1966, e foi membro de várias organizações nacionais e internacionais.

Le Coadic concluiu seus estudos secundários no Liceu Jules Simon Vannes. Graduouse em 1964 em Engenharia dedicando-se aos estudos do Mestrado nessa mesma área. Por meio de uma visita ao Canadá, interessou-se pelo ramo da Ciência da Informação. De volta à França, doutorou-se em "Estrutura e dinâmica dos sistemas de informação científica", gerenciando, a partir de então, programas de pesquisa em Ciência da Informação, e ingressando-se na carreira docente, na Conservatoire National des Arts et Métiers (CNAM) em Paris.

Por fim, Saraceviv nasceu em Zagreb, cidade da antiga Jugoslávia (hoje capital de Croácia) em 1957, graduando-se em Engenharia Elétrica na Universidad de Zagreb. Concluiu o Mestrado em Biblioteconomia no Case Western Reserve University e em 1969 se doutora na mesma instituição, abordando em sua tese, temas relativos à Documentação. Sua carreira profissional está direcionada à docência, como também participa na gestão de diversas associações científicas e na edição de periódicos renomados da área. 


\section{CIÊNCIA DA INFORMAÇÃO: CONCEITOS, CARACTERÍSTICAS E HISTORICIDADE}

Uma definição básica e preliminar para a Ciência da Informação está ancorada na delimitação do objeto por ela estudado, a informação, sendo que esse objeto pode se manifestar e ser estudado em diferentes contextos e sob diversas concepções e abordagens. Tal característica mutante atribuída à informação reflete as problemáticas e dificuldades em se delimitar o escopo de abrangência dessa área do conhecimento, além de problematizar a formulação das bases empíricas e epistemológicas para esse campo do saber (SILVA; RIBEIRO, 2008).

Essa abrangência, diversidade e ambiguidade oriundas do termo informação impactadas aos estudos científicos na área da informação é corroborada por González de Gómes (2003, p. 32), para quem, a Ciência da Informação pode ser definida como um campo abrangente de conhecimento, em que são realizadas pesquisas sobre diversos elementos sociais, contemplando fenômenos, processos, fluxos, “[...] construções, sistemas, redes e artefatos de informação, enquanto informação for definida por ações de informação, as quais remetem aos atores que as agenciam, aos contextos e situações em que acontecem e aos regimes de informação em que se inscrevem".

Considerando uma análise científica acerca do termo informação, entende-se que, a fim de constituir-se como objeto de estudo de um campo de conhecimento, é necessário que a informação seja delineada, haja vista a variedade de concepções e abordagens a que pode se manifestar. Dependendo do contexto, a informação pode ser vista como: 1 - coisa, materializada em um recurso tecnológico; 2 - processo, sustentada em ações comunicativas de transferência; e, 3 - conhecimento, consolidando valor agregado às competências e saberes de um indivíduo (BUCKLAND, 1991).

As diversas abordagens prescritas por Buckland (1991) levam ao entendimento de que a Ciência da Informação se caracteriza como uma área do saber, cujo objeto de investigação contempla a informação em seu aspecto materializado, ou seja, os métodos e técnicas para tratamento e gestão são aplicados apenas à informação quando registrada em um suporte.

Semelhante a Buckland (1991), Bates (2006) também defende essa percepção, afirmando em seus estudos que a informação, em uma análise preliminar, está relacionada a três aspectos, quais sejam: diz respeito a algo organizado, remete à qualidade, atos e tendências e evidencia padrões de comportamento. Nesses três aspectos, a informação se dilui em um vasto universo, dinamizando os elementos naturais como a matéria e a energia. Nessa ramificação, a informação assume, segundo essa autora, variadas formas - o que a torna capaz de ser gerenciada, daí configurar-se como objeto da Ciência da Informação - como: informação sistematizada, organizada, representada, tratada, gravada, rastreada para fins de

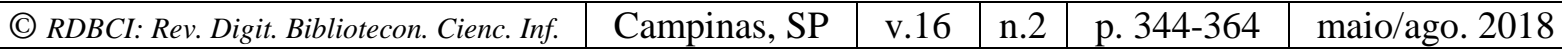




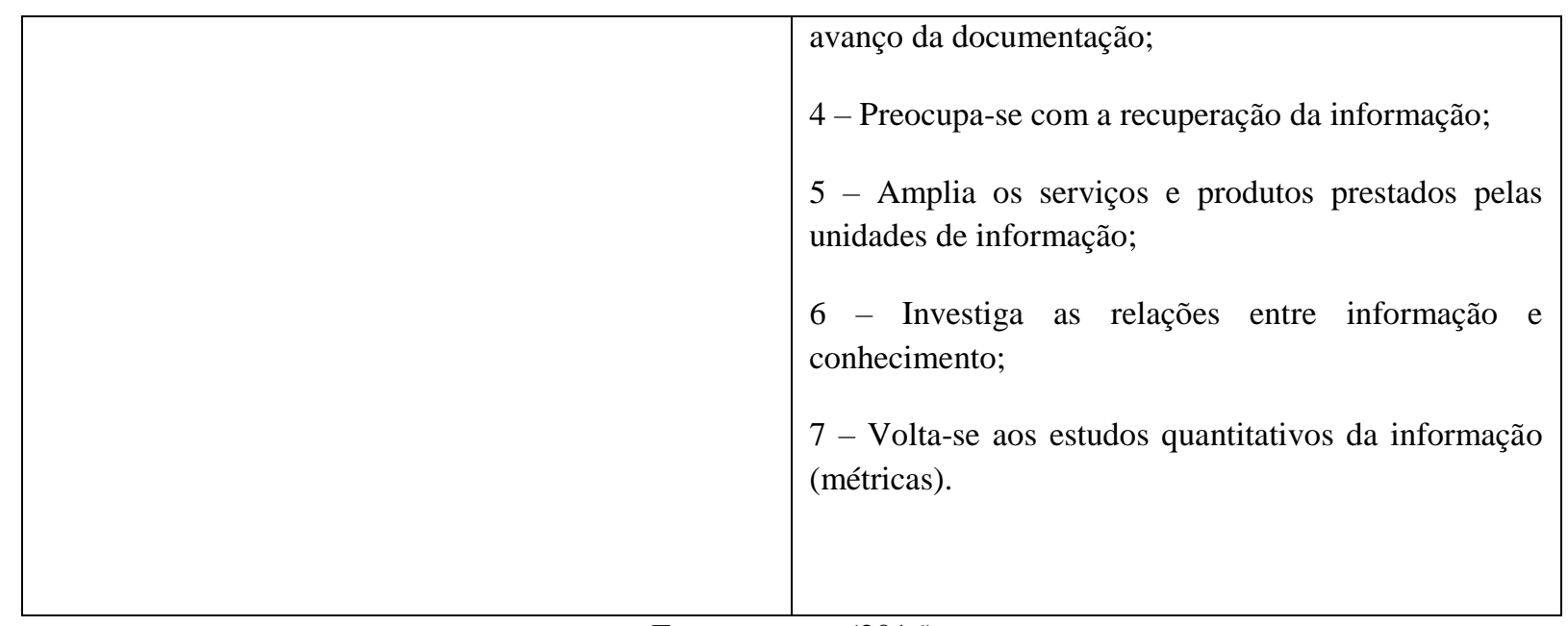

Fonte: o autor (2016)

Com base nos autores descritos no quadro 1, considerando aspectos epistêmicos da Ciência da Informação, sobretudo no que diz respeito às definições, características e percurso histórico, percebe-se que a definição mais apropriada para Ciência da Informação é aquela que considera esse campo do conhecimento como o conjunto de métodos e técnicas utilizados em prol da sistematização da informação registrada, ou seja, a informação documentária. Assim, essa ciência possui ambos os aspectos, ciência pura e aplicada, tendo como um de seus objetivos básicos e primordiais investigar

[...] o corpo de conhecimentos relacionados à origem, coleção, organização, armazenamento, recuperação, interpretação, transmissão, transformação, e utilização da informação. Isto inclui a pesquisa sobre a representação da informação em ambos os sistemas, tanto naturais quanto artificiais, o uso de códigos para a transmissão eficiente da mensagem, bem como o estudo do processamento e de técnicas aplicadas aos computadores e seus sistemas de programação [...] (BORKO, 1968, p. 1-2, tradução nossa).

Embora essa definição seja, talvez, a mais completa, não quer dizer que essa ciência se limita apenas aos registros do conhecimento. Ao contrário, ao longo dos anos, os estudos direcionam-se a aspectos mais complexos, haja vista tornar os sistemas de recuperação mais sofisticados, tendo como foco a satisfação dos usuários da informação, de modo que seja consolidado um processo de otimização quanto ao uso da informação. A partir dessa visão, consolidam-se características acerca do comportamento do ser humano quanto à busca e recuperação da informação, como também, a forma com que essa informação transformar-seá em conhecimento, além dos estudos que versam sobre a melhoria dos sistemas informatizados de recuperação, atividade essa alcançada a partir do desenvolvimento das tecnologias da informação e comunicação (SARACEVIC, 1999).

Essa intervenção ampla da Ciência da Informação, a qual não pode ser limitada à informação documentária, foi introduzida a partir dos conceitos e características iniciais, sendo descrito por Borko (1968, p. 1), como uma disciplina complexa, que contempla todas as fases do ciclo informacional, desde o momento da produção, tramitação e uso, como também todos os fenômenos, processos e elementos que permeiam esse contexto. Assim, a \begin{tabular}{l|l|l|l|l|l} 
(C) RDBCI: Rev. Digit. Bibliotecon. Cienc. Inf. & Campinas, SP & v.16 & n.2 & p. 344-364 & maio/ago. 2018 \\
\hline
\end{tabular} 
Ciência da Informação "[...] investiga as propriedades e o comportamento informacional, as forças que governam os fluxos de informação, e os significados do processamento da informação [...]".

Ao longo dos tempos, com o aumento da competitividade e globalização do mercado, intensifica-se o valor atribuído à informação, tendo em vista sua transformação em conhecimento, agregação de valor para a sociedade como um todo, despertando, dessa forma, estudos no sentido de garantir o armazenamento, recuperação e uso da informação. Assim, manifesta-se a necessidade da gestão da informação, como também, a necessidade do gerenciamento dos recursos informacionais, fato esse que despertou interesses de pesquisas no âmbito das organizações, condicionando novos paradigmas para a área (VAKKARI, 1994).

Assim, a Ciência da Informação direcionou-se rumo à cientificidade, garantindo o gerenciamento da informação e do conhecimento, em todos os segmentos de mercado da sociedade, como também em diversas instituições e organizações. Para tanto, tem se sustentado em diferentes paradigmas, cujo objetivo é viabilizar o uso da informação pelos humanos, sendo que as tecnologias da informação e comunicação, bem como o usuário da informação, representam paradigmas dominantes na área (LE COADIC, 2004b).

Na visão de Le Coadic (2004b), a Ciência da Informação utiliza das tecnologias digitais para facilitar o desenvolvimento da indústria da informação na sociedade, sendo que novos serviços informacionais se ampliam à medida que as redes de colaboração passam a ser utilizadas por pesquisadores, empresas e pela sociedade em geral.

Observa-se, desde seu nascimento, nas últimas décadas do século XX, que a Ciência da Informação evoluiu de uma prática centrada nas técnicas para uma intervenção direcionada ao comportamento humano. Sendo assim, essa ciência transferiu-se, de prática de organização de documentos - característica essa oriunda das ciências documentais, sobretudo da Biblioteconomia - para uma ciência social rigorosa, considerando as demandas sociais emergentes e os novos desafios sociais, como também os grandes avanços da tecnologia da informação. Ademais, os estudos científicos realizados no início por pesquisadores de fora da área e da profissão, como os de Psicologia, Sociologia, Economia, Informática e Telecomunicações, contribuíram, e muito, para o desenvolvimento científico dessa área do saber (LE COADIC, 2004a).

Historicamente, a Ciência da Informação tem sua gênese acoplada aos problemas de recuperação da informação, problemas esses enfrentados por pesquisadores norte-americanos, os quais, diante do volume de conhecimento científico publicado, desenvolveram mecanismos e estratégias para garantir a organização das publicações, como também a recuperação desses itens informacionais, ao serem incorporados a sistemas e bases de dados automatizados (SARACEVIC, 1999; LE COADIC, 2004a). 
Portanto, os problemas oriundos com a explosão informacional, iniciada com a criação da imprensa, ainda no século XV, desencadeou novas formas de registro da informação, ampliando os suportes documentais, como também viabilizou a necessidade de se estabelecer uma disciplina científica para garantir a preservação do conhecimento gerado na sociedade, conhecimento esse intensificado a partir do desenvolvimento científico e das tecnologias digitais (LE COADIC, 2004a).

Nesse aspecto, nota-se que a evolução da Ciência da Informação está alicerçada em três acontecimentos marcantes, que são: a explosão informacional, o desenvolvimento da documentação e os avanços no que se refere às práticas de recuperação da informação. Esses fatos históricos, intensificados no decorrer do século XVIII e XIX, juntamente com as instabilidades econômicas, sociais e políticas promovidas pelos impactos da segunda guerra mundial foram os responsáveis pelo aparecimento de uma disciplina que favorecesse a construção do conhecimento por meio do uso estratégico da informação (SIQUEIRA, 2010).

No entendimento de Saracevic (1996), a disciplina Recuperação da Informação representou um marco, um avanço histórico na Ciência da Informação, principalmente, pelo fato do acúmulo de informações que surgiram no período pós-segunda guerra mundial. Todavia, alguns problemas se consolidaram, tais como: a) como descrever intelectualmente a informação? b) como especificar intelectualmente a busca?, e, por fim, c) que sistemas, técnicas ou máquinas devem ser empregados?

Dessa forma, com a evolução tecnológica dos sistemas de tratamento e recuperação da informação, foram estimuladas "[...] as atividades de armazenamento e recuperação da informação [...]". Portanto, "[...] com a utilização do computador, a Ciência da Informação passou a enfrentar novos desafios [...]” (OLIVEIRA, 2005, p. 15).

Os sistemas de recuperação da informação tornam-se mais eficientes, sendo possível estabelecer estratégias de busca da informação, como também torna-se fácil sua gestão com base nas necessidades e expectativas dos usuários, fato esse que promoveu interações entre cientistas da informação e engenheiros da computação. Assim, a partir da sofisticação desses sistemas é estabelecido "[...] maior número de pontos de acesso, podendo-se, pesquisar por palavras-chave, que aparecem em qualquer ponto do registro, inclusive no resumo e no texto completo quando esses estão disponíveis [...]" (CENDÓN, 2005, p. 62).

Os estudos dos sistemas de recuperação da informação evoluem no sentido de ampliar a preocupação meramente técnica, sendo desenvolvidos esforços para capacitar o ser humano ao uso desses sistemas, sendo eles capazes de serem adequados ao fator humano. Nesse aspecto, para gestão dos sistemas informatizados, faz-se necessário, além do conhecimento técnico, a aquisição de conhecimentos oriundos de outras ciências, tais como os conhecimentos de ciências cognitivas, comunicativas e sociais (OLIVEIRA, 2005). 
Nas últimas décadas, é cada dia mais comum perceber a complexidade dos problemas que permeiam as práticas informacionais, ocorrência essa que permitiu o desenvolvimento de técnicas e métodos específicos, o que condicionou à Ciência da Informação, sua característica interdisciplinar. Destarte, essa ciência busca dialogar com diversos campos do saber, tal como Tecnologia da Informação, Psicologia, Sociologia, História, dentre outras áreas científicas, haja vista unir esforços para a resolução de problemas complexos, não passíveis de resolução por apenas uma área de conhecimento (SILVA; RIBEIRO, 2008).

Com efeito, percebe-se que, ao longo do desenvolvimento da Ciência da Informação, é possível descrever três importantes aspectos inerentes a essa área, quais sejam: a natureza interdisciplinar desse campo científico, o imperativo tecnológico que permeia essa ciência e a sua dimensão social e humana (SARACEVIC, 1996). Segundo esse autor, essas três características ou razões constituem o modelo para compreensão do passado, presente e futuro da Ciência da Informação e dos problemas e questões que essa ciência enfrenta. Assim, tendo como base a evolução dessa área no âmbito das Ciências Sociais Aplicadas e sua interação com outros campos, é possível vislumbrar um futuro promissor para a Ciência da Informação no decorrer das próximas décadas, sobretudo por ela fundamentar-se em abordagens mistas, contemplando aspectos técnicos quanto humanistas.

\section{CIÊNCIA DA INFORMAÇÃO À LUZ DOS ASPECTOS HUMANOS E SOCIAIS}

Embora a Ciência da Informação tenha se sustentado, no decurso de seu processo evolutivo, em três pilares de natureza técnica, qual seja, a explosão informacional, o imperativo tecnológico e a interdisciplinaridade, não quer dizer que ela não venha conquistando, um aspecto cada vez mais humano, voltada para as resoluções dos problemas sociais, portanto, preocupada, também, com questões inerentes à cultura, à memória histórica social, aos direitos e garantias do ser humano etc. (SARACEVIC, 1996, 2009).

Encontra-se nas publicações de Saracevic (1996, 2009) uma discussão que tende a aproximar essa ciência do aparato tecnológico, sobretudo no que se refere ao desenvolvimento da internet, dos sistemas de recuperação da informação e da formação das redes de colaboração. Le Coadic (2004a), em boa parte de suas discussões, também apresenta o aspecto tecnológico como uma tendência atrelada à Ciência da Informação, assim como em Borko (1968) também constata-se a interferência das tecnologias na formação e desenvolvimento dos estudos em informação.

Todavia, mesmo a tecnologia sendo uma das principais características dessa área do saber, há que se considerar, que essas tecnologias são construídas, testadas e usadas, tão somente por humanos; portanto, estudos devem ser desenvolvidos em face do uso desses recursos, considerando sua aplicabilidade para a sociedade e para o benefício do ser humano enquanto elemento que convive em sociedade e utiliza desses recursos para melhorar suas formas de sociabilidade (SARACEVIC, 2009; LE COADIC, 2004a).

\begin{tabular}{l|l|l|l|l|l} 
(C) RDBCI: Rev. Digit. Bibliotecon. Cienc. Inf. & Campinas, SP & v.16 & n.2 & p. 344-364 & maio/ago. 2018 \\
\hline
\end{tabular}


Em síntese, os estudos em informação devem considerar o aspecto humano-social, ou seja, a ciência encarregada pelo gerenciamento da informação, em linhas gerais, "[...] teve e tem um importante papel a desempenhar por sua forte dimensão social e humana, que ultrapassa a tecnologia [...]" (SARACEVIC, 1996, p. 42).

Nessa mesma linha de pensamento, é possível constatar que

A Ciência da Informação, preocupada em esclarecer um problema social concreto, o da informação, e voltada para o ser social que procura a informação, situa-se no campo das ciências sociais (das ciências e do homem e da sociedade), que são o meio principal de acesso a uma compreensão do social e do cultural (LE COADIC, 2004a, p. 19, grifo nosso).

O autor citado relata que, na sociedade da informação, são redefinidos os paradigmas tradicionais que durante séculos sustentaram a dinâmica social. Portanto, o mercado da informação - fortalecido a cada dia com o uso de tecnologias digitais, as quais rompem as delimitações de tempo e de espaço - continua existindo, porém ofertando produtos e serviços informacionais adequados às novidades e potencialidades desses recursos.

Por conseguinte, todos os elementos da sociedade, sobretudo as unidades que prestam serviços e oferecem produtos informacionais, tais como as instituições de pesquisas e as unidades de informação devem acompanhar essa evolução, adequando-se às necessidades solicitadas pelo mercado consumidor. Daí a importância que o ser humano adquire nesse contexto, fato esse que tem considerado o usuário como um dos principais paradigmas da Ciência da Informação, conforme descrito por Le Coadic (2004a).

Nesse enfoque, evidencia-se que

[...] com o advento das tecnologias eletrônicas (análogas ou digitais) e fotônicas da informação (microcomputadores, quiosques interativos, discos laser, fibras óticas, dispositivos multimídias, videodiscos, informática de gestão de acervos et.), as bibliotecas, centros de documentação, museus e instituições culturais, em geral, não podem mais ser apenas depósitos de livros, documentos, objetos e artefatos (LE COADIC, 2004a, p. 17-18, grifo nosso).

Com efeito, a Ciência da Informação passa a ser sustentada por diversos paradigmas. Segundo Le Coadic (2004), essa área de conhecimento apoia-se em diferentes paradigmas que precisam estar em consonância com as necessidades do usuário, considerado como o elemento chave para a melhoria contínua dos produtos e serviços informacionais. $\mathrm{O}$ autor mencionado identifica quatro diferentes paradigmas, que são: paradigma do trabalho coletivo, do fluxo, do uso voltado ao usuário e do elétron.

Esses paradigmas condicionam à Ciência da Informação uma aproximação com os fenômenos de geração, armazenamento, transferência e uso da informação e do conhecimento. Logo, as diversas atividades realizadas nesse contexto, caracterizam esses fenômenos como de natureza infocomunicacionais (LE COADIC, 2004a).

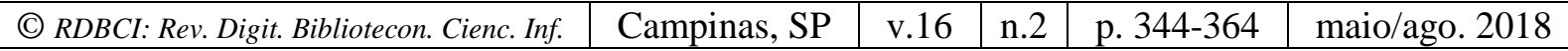


Ao refletir sobre o aspecto comunicacional da informação, o autor considera o processo comunicativo como o objeto de estudo dessa ciência, sendo a informação analisada como um recurso que, ao transmitir mensagens, viabiliza o entendimento de algo, transferência essa realizada de um agente emissor para um receptor, por meio de um canal de comunicação.

Portanto, a informação analisada no âmago da comunicação também considera os usuários como centros das atenções, uma vez que o processo comunicativo somente se concretiza quando produz o processamento da mensagem pelo receptor. São considerados no processo de transmissão de mensagens (comunicação) os usuários envolvidos, o canal de comunicação, formado a partir de um artefato tecnológico e a informação em si, contida nos conteúdos das mensagens (LE COADIC, 2004a).

Portanto, a falta de conexão entre o que se deseja comunicar, o canal comunicativo e os agentes envolvidos representa um entrave na geração de conhecimento, o que requer o estabelecimento de mecanismos capazes de assegurar o verdadeiro sentido contido nas mensagens, bem como as intenções do emissor, como o entendimento do receptor, garantindo, dessa forma, a legitimidade da comunicação (FOX, 1983).

Para Saracevic (2009), a informação como um produto das atividades humanas, condiciona a esse recurso uma construção coletiva, logo, fomentada pelas práticas sociais, daí a importância de se criarem técnicas e métodos para promover o gerenciamento desse produto, haja vista permitir sua preservação para fins de memória, como também viabilizar a produção de conhecimento, contribuindo para a melhoria das práticas sociais e do próprio ser humano.

\subsection{Comportamento informacional: um subcampo da Ciência da Informação em ascensão}

A partir da necessidade de aperfeiçoamento dos sistemas informatizados de recuperação da informação, bem como da melhoria contínua dos produtos e serviços oferecidos nas instituições gerenciadoras de informação, o usuário da informação ganhou maior reconhecimento, sendo considerado como o principal elemento a ser analisado no processo de avaliação, gestão e configuração dos produtos e serviços informacionais (LANCASTER, 2004).

No campo da Ciência da Informação, o valor atribuído ao usuário constituiu a institucionalização de um novo paradigma, que, conjugado ao paradigma tecnológico, proporcionou o nascimento de novos métodos, técnicas e gestão dos recursos informacionais, como apontado nos estudos de Vakkari (1994).

Assim, tendo em vista as questões relativas ao aspecto humano-social, por conseguinte, os estudos sobre comportamento, no âmago da Ciência da Informação, e considerando como

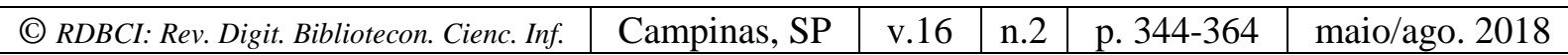


referenciais teóricos básicos as obras de Borko (1968), Le Coadic (2004a, 2004b) e Saracevic (1996, 1999, 2009), é possível delinear algumas temáticas principais contempladas nos estudos desses teóricos, conforme demonstrado no quadro 2.

Quadro 2 - Temáticas analisadas quanto ao aspecto humano-social e comportamento informacional na Ciência da Informação

\begin{tabular}{|c|c|}
\hline REFERENCIAIS TEÓRICOS & PRINCIPAIS TEMÁTICAS CONTEMPLADAS \\
\hline Borko (1968) & 1 - Comportamento, uso e transmissão da informação. \\
\hline Le Coadic (2004a, 2004b) & $\begin{array}{l}\text { 1 - Estudo de uso e usuários; } \\
2 \text { - Relação entre uso e necessidade; } \\
3 \text { - Estudos orientados aos sistemas e aos usuários; } \\
4 \text { - Usuários e a informação no processo } \\
\text { comunicativo. }\end{array}$ \\
\hline Saracevic $(1996,1999,2009)$ & $\begin{array}{l}\text { 1-Ciência social; } \\
\text { 2-Comportamento informacional; } \\
3 \text { - Estudo do uso e de usuários; } \\
4 \text { - Necessidades dos usuários; } \\
5 \text { - Interação homem-computador; } \\
6 \text { - Comunicação humana. }\end{array}$ \\
\hline
\end{tabular}

Fonte: o autor (2016)

Com base nas temáticas contempladas nas obras mencionadas, percebe-se que as pesquisas realizadas pela Ciência da Informação ao longo de sua historicidade vêm desenvolvendo um campo de estudos interdisciplinares, cujo objeto de pesquisa direciona-se aos usuários, suas necessidades e seus comportamentos. Assim, as pesquisas em Ciência da Informação, nas últimas décadas do século XX, despertaram um interesse maior por questões complexas e amplas a respeito da

[...] natureza da informação, a estrutura do conhecimento e seus registros (incluindo bibliometria), o uso e os usuários, levando a estudos do comportamento humano frente à informação; a interação homem-computador, com ênfase no lado humano da equação; relevância, utilidade, obsolescência e outros atributos do uso da informação juntamente com medidas e métodos de avaliação dos sistemas de recuperação da informação; economia, impacto e valor da informação, dentre outros (SARACEVIC, 1996, p. 45, grifo nosso).

Nesse contexto, os estudos acerca do perfil dos usuários e suas necessidades, como também o desempenho dos sistemas de informação tem crescido nos últimos anos, conforme apresentado na revisão sistemática de literatura apresentada por Tuomaala, Järvelin e Vakkari

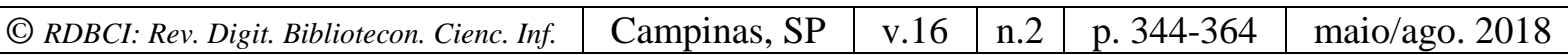


(2014).

Tal crescimento pode ser percebido em virtude de novas abordagens que são delimitadas, como também novos direcionamentos de pesquisa que são estabelecidos dentro desse subcampo da Ciência da Informação, que é o estudo dos usuários e do seu comportamento no processo de busca e recuperação da informação. Assim, mesmo havendo interesse nessa vertente de pesquisa, esse subcampo ainda carece de bases teóricas para fundamentação dos estudos experimentais e empíricos acerca do comportamento do usuário quanto ao uso da informação disponibilizada em sistemas de informação (ROLIM; CENDÓN, 2013).

Para Saracevic (2009), esse subcampo permeia o contexto da Ciência da Informação, sobretudo com o estabelecimento das primeiras abordagens epistemológicas dessa área. Mediante revisão de literatura, o autor detectou que entre 1972 a 1995, esse subcampo era contemplado por disciplinas como Teoria do Usuário (necessidades de informação e usuários), e entre 1996 a 2006, surgem novas disciplinas preocupadas com os estudos de usuários (busca de informações/comportamento de busca, abordagem centrada no usuário para recuperação da informação, usuários e uso) e com o julgamento de relevância de usuários (relevância situacional).

As pesquisas publicadas no final do século XX e início do século XXI demonstraram um crescimento gradativo no que se refere ao estudo dos usuários. Para Saracevic (2009, p. 4, tradução nossa), no campo científico da Ciência da Informação, “[...] três áreas de maior e contínuo interesse são estudos de recuperação de informação, usuários e de uso e estudos de métricas $[\ldots] "$ ".

A complexidade envolta a esse subcampo despertou ainda mais a necessidade de interação com outras disciplinas, sobretudo as disciplinas cognitivas, as quais fornecem teorias acerca do comportamento humano e as interações do ser humano em face da transferência da informação, seja na relação entre humanos ou na relação homem/máquina (SARACEVIC, 1996, 2009).

No entanto, é preciso frisar que a preocupação com o uso e usuário da informação, por conseguinte, as pesquisas sobre comportamento informacional têm sua gênese nas primeiras publicações sobre Ciência da Informação, momento esse em que os estudos de usuários e de comunidade passam a ser uma preocupação, também, da Biblioteconomia e áreas afins (SARACEVIC, 1996).

Para Borko (1996), o cientista da informação tem um escopo de investigação muito amplo. Dentre as diversas linhas de investigação, a grande maioria decorre dos procedimentos técnicos utilizados para viabilizar tratamento e recuperação da informação, no entanto, no que se refere às questões humano-social, a Ciência da Informação desenvolve

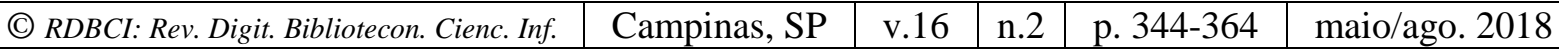


estudos direcionados a necessidades de informação e usos, estudos de comportamento de usuários, estudos de citação, padrões de comunicação e estudos de uso literários.

O termo comportamento informacional foi mencionado por Borko (1968, p. 4, grifo nosso, tradução nossa), na década de 1960, quando descreveu que a Ciência da Informação, em essência, é definida como a ciência que "[...] investiga as propriedades e o comportamento da informação, o uso e a transmissão da informação e o processamento da informação, visando uma armazenagem e uma recuperação ideal”.

O comportamento diz respeito ao posicionamento de um indivíduo quando esse procura por informação a fim de preencher seu estado anômalo de conhecimento. Todavia, no entendimento de Le Coadic (2004a), há distinção nos termos uso e usabilidade, bem como estudos de usuários e de uso. Para o referido autor:

[...] Usar informação é trabalhar com a matéria informação para obter um efeito que satisfaça a uma necessidade de informação. Utilizar um produto de informação é empregar tal objeto para obter, igualmente, um efeito que satisfaça a uma necessidade de informação, quer esse objeto subsista (fala-se, então, de utilização), modifique-se (uso) ou desapareça (consumo) (LE COADIC, 2004a, p. 39).

Com efeito, a finalidade de um produto, sistema ou serviço de informação deve girar em torno das questões relativas ao uso da informação e dos efeitos oriundos desse uso nas atividades realizadas pelos usuários. Portanto, a função principal dos sistemas de informação é a forma como a informação modifica a realização dessas atividades (LE COADIC, 2004a).

Nesse contexto, a obra de Le Coadic (2004a), semelhante a Borko (1968) e Saracevic (1996, 2009), também contempla a importância do usuário e seu comportamento em face do uso dos sistemas, serviços e produtos de informação. Assim, as relações existentes entre uso e necessidade "[...] são interdependentes, se influenciam reciprocamente de uma maneira complexa que determinará o comportamento do usuário e suas práticas" (LE COADIC, 2004a, p. 39).

No entendimento de Saracevic (2009) e considerando as reflexões propostas por Le Coadic (2004a), os estudos do comportamento do usuário, bem como de suas necessidades, devem ser orientados pela demanda (com foco no sistema) quanto para o próprio usuário. Todavia, para Le Coadic (2004a), os estudos orientados ao sistema não são suficientes, uma vez que não analisam as necessidades de informação. Portanto, o autor recomenda a importância de se estudar previamente o usuário, pois é através do conhecimento de suas expectativas, que serão conhecidas suas necessidades, por conseguinte, os sistemas serão gerenciados conforme finalidades específicas, considerando o perfil da comunidade usuária.

Ao se realizarem estudos de uso e usuários da informação, afere-se o conhecimento acerca do perfil e do comportamento do usuário, fato esse que representa uma das mais importantes estratégias utilizadas na coleta de dados para a melhoria dos sistemas

\begin{tabular}{|c|c|c|c|c|c|}
\hline (C) RDBCI: Rev. Digit. Bibliotecon. Cienc. Inf. & Campinas, SP & v.16 & n. 2 & p. $344-364$ & maio/ago. 2018 \\
\hline
\end{tabular}


informatizados de busca e recuperação da informação. Portanto, o estudo do comportamento do usuário na busca por informação constitui uma das temáticas de maior relevância para a área e que vem crescendo gradativamente ao longo dos anos, englobando "[...] uma ampla gama de processos que as pessoas empregam quando envolvidas com a informação e para os estados e efeitos cognitivos e sociais relacionados [...]" (SARACEVIC, 2009, p. 13, tradução nossa).

O autor acima citado demonstra a complexidade envolvida nesses estudos, o que requer o constante aperfeiçoamento de métodos e técnicas para coleta de dados, bem como a utilização de diversas abordagens teóricas, tal como evidenciado por Rolim e Cendón (2013).

Tendo em vista essas complexidades e a necessidade de ampliação dos estudos nesse subcampo da Ciência da Informação, de acordo com Saracevic (2009), cada vez mais, tornase válido a colaboração de diversas áreas do saber na resolução dos problemas relativos ao uso da informação e sua interferência nas práticas sociais da contemporaneidade.

Assim, a cooperação entre as diversas áreas do conhecimento representa uma estratégia para a resolução dos problemas informacionais, proporcionando, dessa forma, melhorias quanto à intervenção da Ciência da Informação na sociedade. Portanto, evidencia-se que, no contexto social como um todo, "[...] as atividades profissionais e científicas desempenhadas pela Ciência da Informação são necessárias [...]” (SARACEVIC, 1996, p. 60), o que lhe confere um futuro promissor. Por conseguinte, conforme proferido por Saracevic (1999), ao colocar-se a serviço das causas sociais, essa ciência tende a ampliar seus interesses de pesquisa, sendo redefinida, reestruturada e reinventada, preenchendo as necessidades, desejos e expectativas dos diversos usuários da informação.

\section{CONSIDERAÇÕES FINAIS}

A análise nos referenciais bibliográficos contemplados no percurso metodológico deste artigo ajudou-nos a reforçar a essência da Ciência da Informação, seus princípios básicos de sustentação, bem como seu desenvolvimento ao longo dos tempos, caracterizando esse campo de conhecimento científico direcionado à resolução de problemas informacionais, o que viabiliza seu reconhecimento e aplicabilidade na sociedade atual.

Os aspectos epistemológicos aqui analisados definem a Ciência da Informação como uma ciência que estuda o objeto informação e os procedimentos para coleta, armazenagem e uso desse recurso, caracterizando-se como uma ciência interdisciplinar, influenciada pelas tecnologias da informação e comunicação, e as origens desse campo científico remetem aos reflexos do desenvolvimento científico e tecnológico do século XX.

Os resultados obtidos com a análise nos aspectos sociais e humanos evidenciaram que os 
estudos das necessidades e do uso da informação, com foco no usuário, viabilizam a importância do ser humano, como principal elemento do processo informacional, sendo que as pesquisas vêm se aperfeiçoando, em que são investigadas questões comportamentais quanto ao uso dos recursos, produtos, serviços e sistemas de informação.

Por análise comparativa entre as três referências teóricas é possível constatar, em linhas gerais, similaridades quanto aos conceitos, características e história da Ciência da Informação, como também, percebeu-se que os estudos sobre comportamento informacional acompanham a trajetória evolutiva, fortalecendo-se no decorrer dos tempos, a ponto de se consolidar com um amplo e aprofundado subcampo dessa ciência.

Mesmo havendo vasto período de tempo entre as publicações dos autores analisados, de 1968 a 2009, de modo geral, as discussões apresentadas nas temáticas analisadas permanecem as mesmas, o que demonstra ser esses temas a base epistêmica, a essência da Ciência da Informação, sendo que essa ciência, ao longo dos tempos, fidelizou em estudar esses temas, consolidando seu campo de conhecimento e legitimando suas práticas de investigações em temáticas específicas atreladas ao âmbito informacional.

Com efeito, a questão do comportamento informacional no âmbito da Ciência da Informação tem como foco o usuário, no entanto, comunga de aspectos técnicos quanto humanistas para poder melhorar a qualidade e excelência quanto à oferta de informação, fato esse que confirma a participação dessa ciência no desenvolvimento da sociedade, sobretudo ao valorizar a vertente sociocultural e humanista como um de seus paradigmas contemporâneos.

A natureza limitada da metodologia aqui estabelecida viabiliza a continuação da pesquisa, sendo recomendada, a posteriori, uma revisão de literatura com uma amostra mais abrangente, com autores nacionais e internacionais acerca de como o tema comportamento informacional vem sendo tratado nos últimos anos. Além disso, espera-se realizar estudos aplicados em campo, acerca do comportamento e percepção dos usuários, no que tange ao uso de sistemas de informação informatizados, tal como a busca por informação nos portais de periódicos científicos.

\section{REFERÊNCIAS}

BATES, Marcia. Fundamental Forms of Information. Journal of the Association for Information Science and Technology, v. 57, n. 8, p. 1033-1045, 2006.

BORKO, Harold. Information Science: what is it? American Documentation, v. 19, n. 1, p. 3- 5, jan. 1968.

BUCKLAND, Michael. Information as thing. Journal of American Society for Information Science. n. 42, v.5, p. 351-360, 1991. 
CAPURRO, Rafael. Hermeneutic sand the phenomenon of information. Research in Philosophyand Technology, v. 19, p. 79-85, 2000.

CENDÓN, Beatriz Valadares. Sistemas e redes de informação. In: OLIVEIRA, Marlene de (Coord.). Ciência da informação e biblioteconomia: novos conteúdos e espaços de atuação. Belo Horizonte: UFMG, 2005. p. 45-75.

FOX, Chris. Information and Misinformation: An Investigation of the Notions of Information, Misinformation, Informing, and Misinforming. In: Information and propositions. Westport: Greenwood, 1983. p. 74-108.

GONZÁLEZ DE GÓMEZ, Maria Nélida. Escopo e abrangência da Ciência da informação e a pós-graduação na área: anotações para uma reflexão. Transinformação, Campinas, v.15, n.1, p. 31-43, jan./abr. 2003. Disponível em: <http://basessibi.c3sl.ufpr.br/brapci/v/a/173>. Acesso em: 25 nov. 2016.

LANCASTER, Frederick Wilfrid. Indexação e resumos: teoria e prática. 2. ed. Brasília: Briquet de Lemos, 2004.

LE COADIC, Yves François. A ciência da informação. 2. ed. Brasília: Briquet de Lemos, 2004a.

LE COADIC, Yves François. Princípios científicos que direcionam a ciência e a tecnologia da informação digital. Transinformação, Campinas, v. 16, n. 3, p. 205-213, 2004b.

Disponível em: 〈http://www.scielo.br/pdf/tinf/v16n3/01.pdf>. Acesso em: 25 nov. 2016.

OLIVEIRA, Marlene de. Origens e evolução da Ciência da Informação. In: (Coord.). Ciência da Informação e Biblioteconomia: novos conteúdos e espaços de atuação. Belo Horizonte: UFMG, 2005. p. 9-28.

RADAMÉS LINARES, Columbié. Ciencia de laInformación: su historia y epistemología. Bogotá, Colombia: Editorial Rojas Eberhard, 2005.

ROLIM, Elizabeth Almeida; CENDÓN, Beatriz Valadares. Modelos teóricos de estudos de usuários na ciência da informação. DataGramaZero, v. 14, n. 2, 2013. Disponível em: <http://basessibi.c3sl.ufpr.br/brapci/v/a/11781>. Acesso em: 24 nov. 2016.

SARACEVIC, Tefko. Ciência da informação: origem, evolução e relações. Perspectiva em Ciência da Informação, Belo Horizonte, v. 1, n. 1, p. 41-62, jan./jun. 1996. Disponível em: <http://www.brapci.inf.br/index.php/article/download/11621>. Acesso em: 17 mar. 2016.

SARACEVIC, Tefko. Information Science. Journal of the american society for information science, v. 50, n. 12, p. :1051-1063, 1999.

SARACEVIC, Tefko. Information Science. In: BATES, Marcia; MAACK, Mary Niles (Ed.). Encyclopedia of Library and Information Science. New York: Taylor \& Francis, 2009. p. 2570-2586. 
SHERA, Jesse. The sociological relation ships of information science. Journal of the American Society for information science, v. 22, n. 1, p. 76-80, mar./abr. 1971.

SILVA, Armando Malheiro da; RIBEIRO, Fernanda. Das ciências documentais à ciência da informação: ensaio epistemológico para um novo modelo curricular. 2, ed. Porto: Afrontamento, 2008.

SIQUEIRA, Jéssica Câmara. Biblioteconomia, documentação e ciência da informação: história, sociedade, tecnologia e pós-modernidade. Perspectivas em Ciência da Informação, v. 15, n. 3, p. 52-66, set./dez. 2010. Disponível em:

<http://www.scielo.br/pdf/pci/v15n3/04.pdf >. Acesso em: 17 mar. 2016.

TUOMAALA, Otto; JÄRVELIN, Kalervo; VAKKARI, Pertti. Evolution of Library and Information Science, 1965-2005: Content Analysis of Journal Articles. Journal of the association for information science and technology, v. 65, n. 7, p. 1446-1462, 2014.

VAKKARI, Pertti. Library and Information Science: Its Contentand Scope. In: GODDEN, Irene (Org.). Advances in librarianship. San Diego, 1994.

VERGARA, Sylvia Constant. Projetos e Relatórios de Pesquisa em Administração. São Paulo: Atlas, 2007.
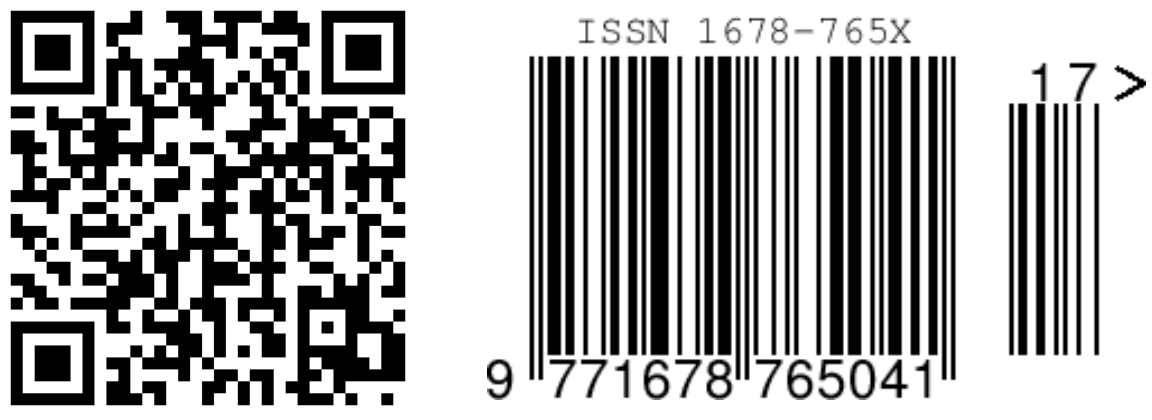